\title{
Fuzzy-based Field-programmable Gate Array Implementation of a Power Quality Enhancement Strategy for ac-ac Converters
}

\author{
N. Radhakrishnan ${ }^{\dagger}$ and M. Ramaswamy*
}

\begin{abstract}
In the present work, a new approach is proposed for via interconnects of semiconductor devices, where multi-wall carbon nanotubes (MWCNTs) are used instead of conventional metals. In order to implement a selective growth of carbon nanotubes (CNTs) for via interconnect, the buried catalyst method is selected which is the most compatible with semiconductor processes. The cobalt catalyst for CNT growth is pre-deposited before via hole patterning, and to achieve the via etch stop on the thin catalyst layer (ca. $3 \mathrm{~nm}$ ), a novel 2-step etch scheme is designed; the first step is a conventional oxide etch while the second step chemically etches the silicon nitride layer to lower the damage of the catalyst layer. The results show that the 2-step etch scheme is a feasible candidate for the realization of CNT interconnects in conventional semiconductor devices.
\end{abstract}

Keywords: Carbon nanotubes, Via interconnects, Selective growth, Two-step etch, Physical and chemical reactions

\section{Introduction}

In a generic form, a power electronic ac-ac converter accepts electric power from one system and delivers it to another system with waveforms of different amplitude, frequency, and phase. These power converters are extensively used in a wide spectrum of applications, such as adjustable speed drives (ASDs), static VAR generators, alternative energy systems, and uninterruptible power supplies. However, by their very principle of operation, these converters inject characteristic and circuit-dependent harmonics into the source and generate interharmonics at the output. Highly distorted input currents cause a significant deterioration of electric power quality.

A variety of sophisticated control schemes have been developed to alleviate the ill effects of harmonics [1]. A host of switching methods (viz., symmetrical angle control [2], asymmetrical angle control [3], and high-frequency time ratio control) have been proposed to eliminate harmonic-related problems. A host of techniques, such as uniform PWM, sinusoidal PWM (SPWM), random PWM (RPWM), and others, have been used to reduce lower-order harmonics of PWM converters [4,5]. A single-phase capacitor clamped ac-ac converter with hysteresis current control offers dc voltage regulation and near-unity input power factor [6]. A novel robust control technique for PWM ac choppers with the ability to generate high-quality sinusoidal waveforms with amplitude that is adjustable over a wide range of control has been developed [7]. The designed deadbeat control algorithm enjoys the advantages of fast time response and compensates effectively the effects of nonlinear loads. An improved technique with a voltage-controlled loop to eliminate voltage distortion has been suggested [8]. A new control technique has been implemented in a single-phase ac-ac converter built with a rectifier and an inverter to yield power factor compensation and a good dynamic performance [11]. A novel method has been developed to effectively improve the power factor and power transfer efficiency of an ac-ac converter [12].

A voltage source PWM ac-ac converter has been built to eradicate input harmonics caused by capacitor input rectifier [9]. A single-stage high-frequency soft-switching ac-ac converter has been proposed to achieve harmonic current suppression and inherit unity power factor capability [10]. A new harmonic mitigating scheme based on 24-pulse acdc conversion has been implemented through a voltage source inverter supplying squirrel-cage induction motor drive [14]. A new technique where the bidirectional switches in a three-phase controlled rectifier switched at double the line frequency to achieve unity power factor has also been described [15].

Although existing control strategies competently address the output distortions, they are not successful in suppressing the dominant harmonics present in the input current. In addition, the presence of lower-order harmonics creates a poor-quality output spectrum, which in turn results in current ripple. Therefore, a fairly new PWM strategy suitable for the power switches in ac voltage controller is generated using the state-of-the-art field-programmable gate array (FPGA) processor to achieve the desired power quality.

\section{Problem Formulation}

The objective is to suppress the harmonic distortion and $\dagger \quad$ Corresponding Author: Dept. of Electrical Engineering, Annamalai

* Dept. of Electrical Engineering, Annamalai University, Tamil Nadu, India (aupowerstaff@gmail.com)

Received: December 11, 2009; Accepted: January 19, 2011 
improve the overall power quality of an ac-ac converter system through the use of a proposed PWM (PPWM) technique generated using a fuzzy control algorithm. This technique is proposed for designing a control strategy to extract the PWM pulses for the power switches in the IGBT-based ac-ac converter that attempts to improve the overall power quality in addition to regulating its output voltage over a wide range of load variations. Implementation of the scheme through the use of the state-of-the-art processor FPGA is envisioned.

\section{Proposed Approach}

The switching action of the PWM converter generates higher-order harmonics at the output. The input current distortion in the converter limits the amplitude of the fundamental and introduces unexpected lower-order harmonic components. Our proposed approach is to implement a PPWM strategy that is inherently capable of eliminating the harmonic content to enhance the overall power quality. The fuzzy logic controller introduced in the feedback path is coined to extract an appropriate value for the reference wave which, when superimposed over the derived carrier, generates suitable firing pulses that in turn contribute to accomplish the desired objective.

\section{Switching Strategy}

The power circuit of a PWM ac-ac converter shown in Fig. 1 comprises a bidirectional power switch to regulate the power delivered to the load. When a switching function is applied to the gate of the power switch, the output voltage appears in the PWM form at the load terminals.

This form of PWM is designed to produce an approximately sinusoidal load current. The corresponding input current has a PWM form distributed over a whole cycle. The fundamental voltage can be adjusted according to the required duty cycle. The harmonics are suppressed in proportion to the difference between the frequencies of the ac line voltage and the modulating frequency.

The relationship between the input and output voltage,

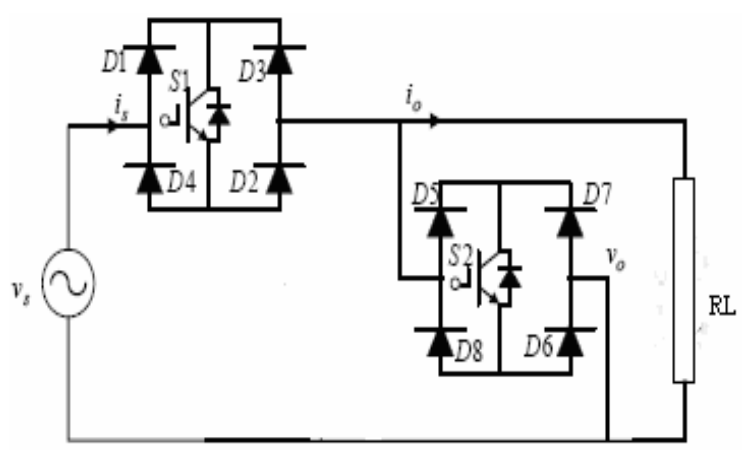

Fig. 1. The ac voltage controller power circuit. for a given control function, can be expressed as

$$
V_{0}(\theta)=\alpha(\theta)=V_{s} \sin \theta
$$

where the input voltage is of the form

$$
V_{s}(\theta)=\sqrt{2} V_{s} \sin \theta
$$

The most desirable output voltage is a pure sinusoidal wave with variable amplitude:

$$
V_{0}(\theta)=\sqrt{2} V_{0} \sin \theta
$$

The ideal switching function for an ac voltage controller to satisfy Eqs. (1) and (2) is a constant value represented with a fixed parameter $x_{0}$ and limited to a control range $[0,1]$. It is thus a value equivalent to the output voltage to be obtained:

$$
\alpha_{1}(\theta)=x_{0}
$$

The output voltage is regulated ideally over the full range $\left[0, V_{\mathrm{s}}\right]$ by changing the values of $x_{0}$ and has no harmonics within that range. The desired PWM is obtained by modulating $\alpha_{1}$ by a triangular carrier wave composed of multiple pulses of equal width. The pulse number for a full wave of the ac source is the same as the ratio of the carrier frequency to the source frequency.

The switching function has quarterwave symmetry, and is unipolar compared with the polarity of the ac source. Thus, a Fourier series for the function for any " $m$ " (where " $m$ " is the number of pulses per half cycle) can be expressed as

$$
\alpha(\theta)=\frac{\gamma}{2}+\sum_{m=2}^{\alpha} \gamma_{m} \cos m \theta
$$

The coefficients for any even value of " $m$ " are

and

$$
\begin{gathered}
\gamma_{0}=\frac{4}{\pi}\left\{\frac{\pi \delta}{2}+\sum_{k=1}^{M}(-1)^{k} . x_{k}\right\} \\
\gamma_{m}=\frac{4}{m \pi} \sum_{k=1}^{M}(-1)^{k} \sin m x_{k} \\
\delta=1 \quad \text { for odd } M \\
\delta=0 \quad \text { for even } M
\end{gathered}
$$

Therefore, the expressions of $V_{0}$ is simplified from Eqs. (1) and (4) as

$$
V_{0}(\theta)=\sqrt{2} V_{s} \sum_{m=2}^{\alpha} A_{n} \sin n \theta
$$




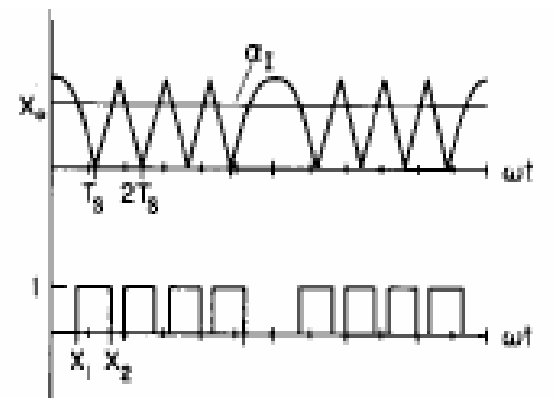

Fig. 2. Proposed PWM switching pattern.

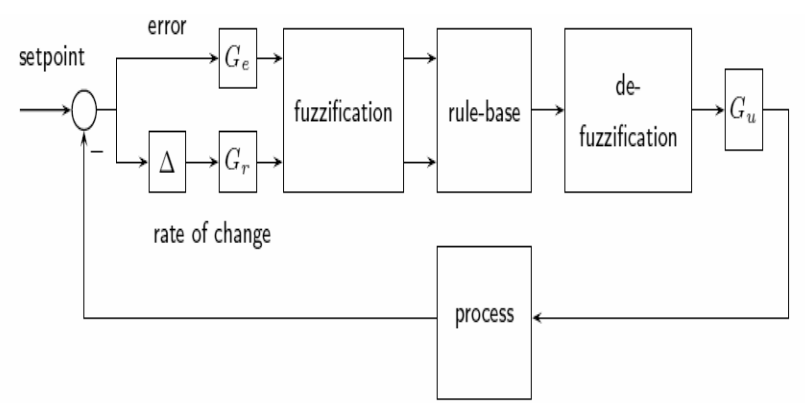

Fig. 3. Fuzzy logic controller.

Table 1. Fuzzy decision matrix

\begin{tabular}{|c|c|c|c|c|c|c|c|c|}
\hline \multirow{2}{*}{\multicolumn{2}{|c|}{ AND }} & \multicolumn{7}{|c|}{$\mathrm{CE}$} \\
\hline & & NB & $\mathrm{NM}$ & NS & $\mathrm{ZO}$ & PS & $\overline{P M}$ & PB \\
\hline \multirow{7}{*}{$E$} & NB & $\mathrm{XB}$ & $\mathrm{NB}$ & $\mathrm{NB}$ & $\mathrm{NB}$ & $\mathrm{NM}$ & NS & $Z \mathrm{Q}$ \\
\hline & $\mathrm{NM}$ & $\mathrm{AB}$ & $\mathrm{AB}$ & $\mathrm{AB}$ & $\mathrm{NM}$ & $\mathrm{NS}$ & $\mathrm{Z} Q$ & $\mathrm{PS}$ \\
\hline & NS & $\mathrm{NB}$ & $\mathrm{NB}$ & $\mathrm{NM}$ & $\mathrm{NS}$ & 70 & $\mathrm{PS}$ & $\mathrm{PM}$ \\
\hline & $\mathrm{ZO}$ & $\mathrm{NB}$ & $\mathrm{M}$ & NS & $Z Q$ & $\mathrm{PS}$ & $\mathrm{PM}$ & $\mathrm{PB}$ \\
\hline & PS & $\mathrm{NM}$ & $\mathrm{NS}$ & $\mathrm{zO}$ & $\mathrm{PS}$ & $\mathrm{PM}$ & $\mathrm{PB}$ & $\mathrm{PB}$ \\
\hline & $\mathrm{PM}$ & $\mathrm{NS}$ & $\mathrm{Z} O$ & $\mathrm{PS}$ & $\mathrm{PM}$ & $\mathrm{PB}$ & $\mathrm{PB}$ & $\mathrm{PB}$ \\
\hline & PB & $z 0$ & $P S$ & $\mathrm{PM}$ & $\mathrm{PB}$ & $\mathrm{PB}$ & $\mathrm{PB}$ & $P \mathrm{~B}$ \\
\hline
\end{tabular}

For odd number $n$, the coefficient $A_{n}$ is obtained from Eqs. (5), (6), and (9) as

$$
A_{n}=\left(\gamma_{m-2}-\gamma_{m}\right) / 2
$$

Consequently, the expressions for $A_{1}$ (for fundamental order) and $A_{n}$ (for harmonics) are expressed as

$$
\begin{gathered}
A_{1}=\frac{2}{\pi}\left\{\frac{\pi \delta}{2}+\sum_{k=1}^{M}(-1)^{k} \bullet\left(x_{k}-\frac{1}{2} \sin 2 x_{k}\right\}\right. \\
A_{n}=\frac{2}{\pi} \sum_{k=1}^{M}(-1)^{k} \bullet\left\{\frac{\sin (n-1) x_{k}}{n-1}-\frac{\sin (n+1) x_{k}}{n+1}\right\}
\end{gathered}
$$

The PWM switching points are determined by solving the above equations for different values of the control variable $x_{0}$. The switching points, except for $x_{1}$, varies line- arly with $x_{0}$ within the full control range. A new carrier wave is thus derived from the computed switching points from which the PWM switching pattern seen in Fig. 2 is produced.

The firing pulse algorithm is coined in such a way that the pulses do not appear at the zero crossings of the input sine wave. Thus, considerable reduction in the harmonic content and consequently a significant lowering of the total harmonic distortion occur. Because the proposed switching scheme facilitates a considerable increase of the fundamental component and the light of the fact that the fuzzy logic controller (FLC) forces the input current vector closer to the voltage wave, the input power factor is improved.

\section{Fuzzy Logic Controller}

Fuzzy logic offers a powerful and flexible mechanism through which viable decisions can be extracted to solve real-world problems. The key components of fuzzy system knowledge base are a set of IF-THEN rules obtained from human knowledge and expertise. The underlying strength of fuzzy logic is that it makes use of linguistic variables rather than numerical values to represent imprecise data.

The FLC shown in Fig. 3 generates the firing pulses using the reference obtained from the output fuzzy variable, the control vector " $u$," and the derived carrier. The two inputs to the fuzzy algorithm are (i) the error (e) between a reference voltage and the actual load voltage, which droops because of the increase in current, and (ii) the change in error (ce). This is precisely the difference between the error at a certain operating point and the preceding error.

The fuzzy terms describing the identified variables are negative big (NB), negative medium (NM), negative small (NS), zero (ZO), positive small (PS), positive medium (PM), and positive big (PB). The sets defining the e, ce, and $\mathrm{u}$ are as follows:

$$
\begin{aligned}
& \mathrm{e}=\{\mathrm{NB}, \mathrm{NM}, \mathrm{NS}, \mathrm{ZO}, \mathrm{PS}, \mathrm{PM}, \mathrm{PB}\} \\
& \mathrm{ce}=\{\mathrm{NB}, \mathrm{NM}, \mathrm{NS}, \mathrm{ZO}, \mathrm{PS}, \mathrm{PM}, \mathrm{PB}\} \\
& \mathrm{u}=\{\mathrm{NB}, \mathrm{NM}, \mathrm{NS}, \mathrm{ZO}, \mathrm{PS}, \mathrm{PM}, \mathrm{PB}\}
\end{aligned}
$$

A one-dimensional triangular membership function is chosen for input and output linguistic variables. The rules are summarized in the fuzzy decision matrix in Table 1. The consequents of the rules are shown in the shaded part of the matrix. The fuzzy results must be defuzzified through a defuzzification process to achieve a crisp numerical value. The most commonly used centroid or center of gravity defuzzification strategy is thus adopted.

\section{Simulation}

The scheme was simulated using MATLAB-SIMULINK with the power circuit rated at $230 \mathrm{~V}, 5 \mathrm{KW}$. The derived PPWM pulses appearing in Fig. 4a facilitate the desired 


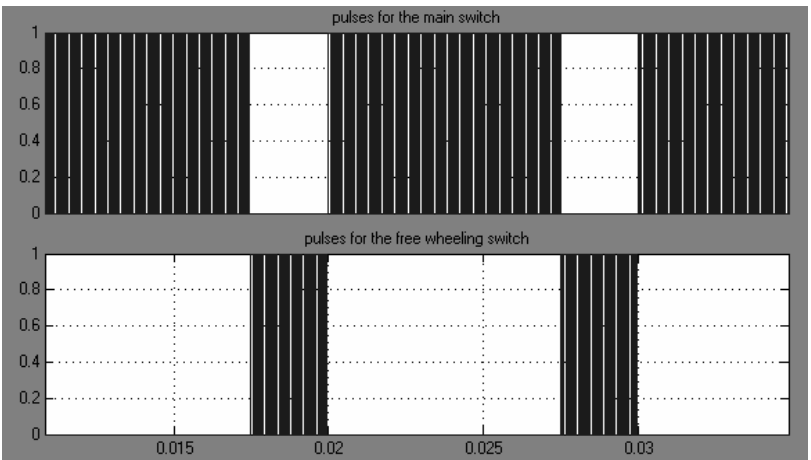

Fig. 4a. Simulated PWM pulses.

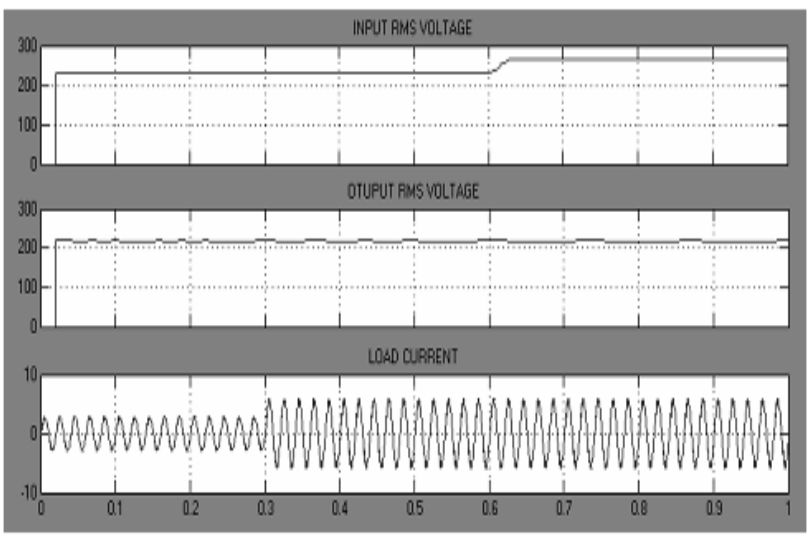

Fig. 4b. Response waveforms.

output rms voltage through the IGBT power switches from the available sinusoidal ac source. The rms input and output voltages along with the load current waveforms are depicted in Fig. 4b.

The figure above shows that when a $10 \%$ change in the load is suddenly introduced at $0.3 \mathrm{~s}$ to the steady-state response, the load current increases and settles rapidly at the new value. However, because of the action of the controller, the output voltage remained regulated during the load disturbance and continued to remain regulated even in the event of an occurrence of a $10 \%$ disturbance in the source voltage created at $0.6 \mathrm{~s}$.

The frequency spectrum seen in Fig. $5 \mathrm{a}$ and $5 \mathrm{~b}$ and the graph depicted in Fig. 6b obtained using both SPWM and PPWM, for the same operating state, reveals that the effect of source voltage distortion expressed as a measure of THD is much lower in the case of PPWM. The input power factor characterized as a function of the THD of the input current is improved. The graph relating input power factor and the load current seen in Fig. 6a justifies the claim and brings out the superiority of PPWM.

\section{Hardware Implementation}

The block diagram for the proposed topology seen in Fig. 7 explains the basic philosophy of the designed scheme.

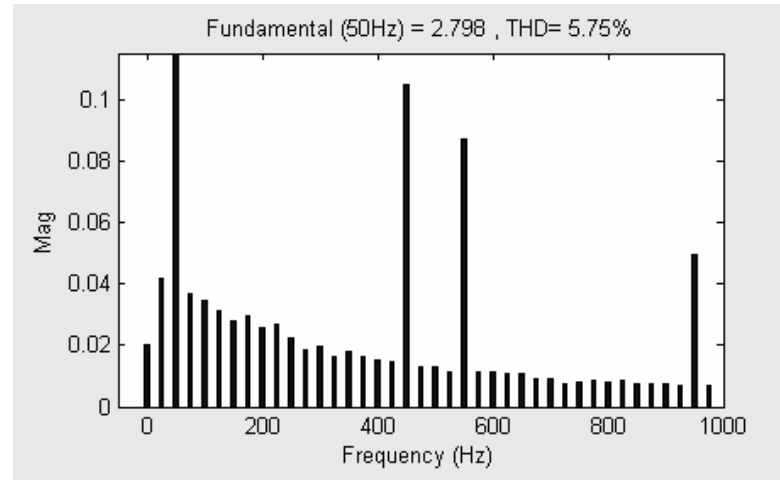

Fig. 5a. SPWM frequency spectrum.

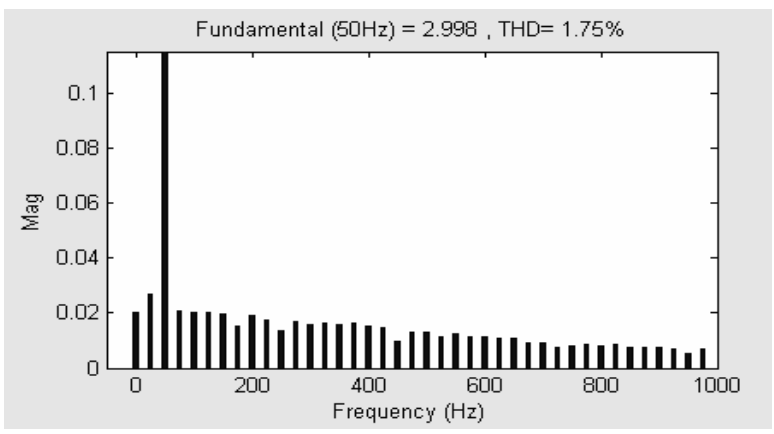

Fig. 5b. PPWM frequency spectrum.

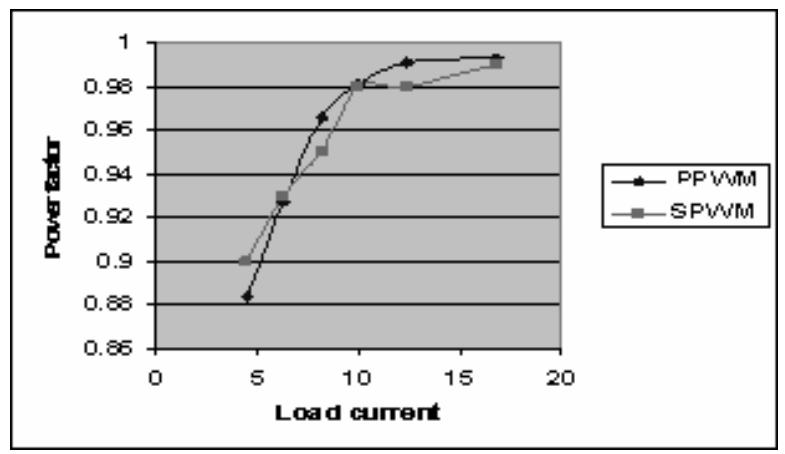

Fig. 6a. Relation between load $\mathrm{Ct}$ and power factor.

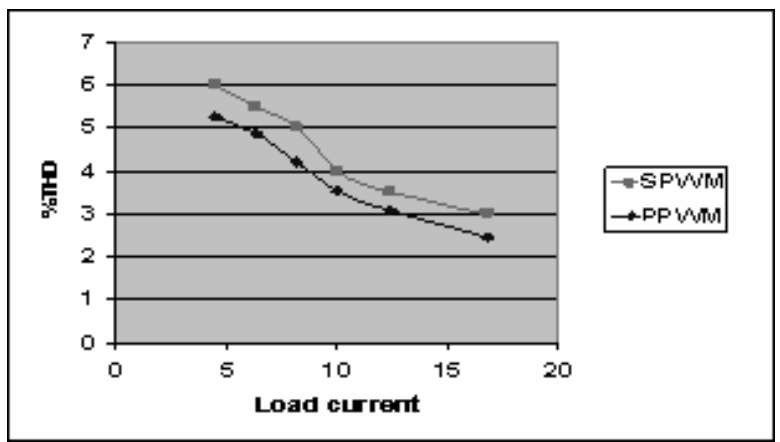

Fig. 6b. Relation between load $\mathrm{Ct}$ and THD.

The prototype model in Fig. 8 is built and tested for similar values of load powers. The FPGA belongs to the wide fam- 


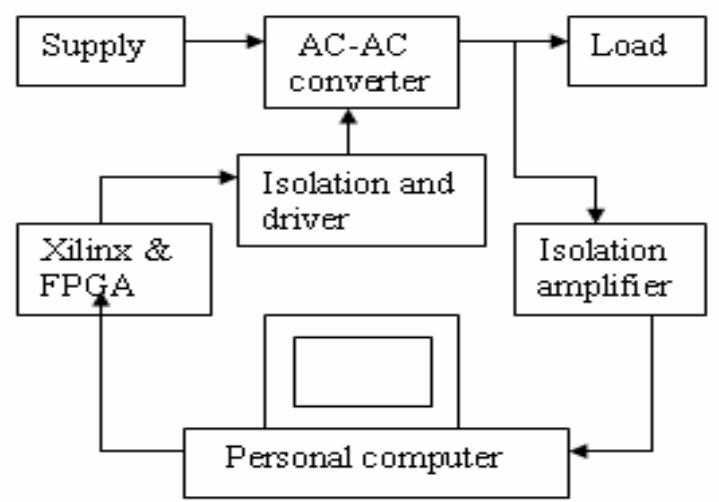

Fig. 7. Block diagram.

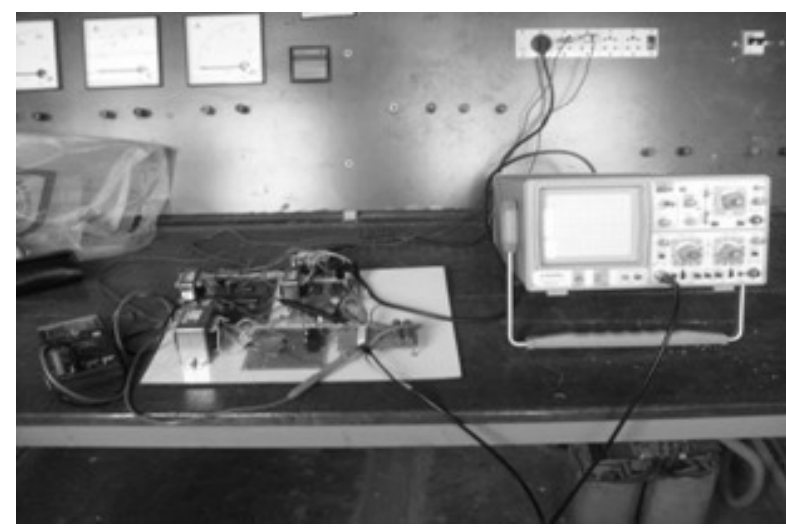

Fig. 8. Prototype model.

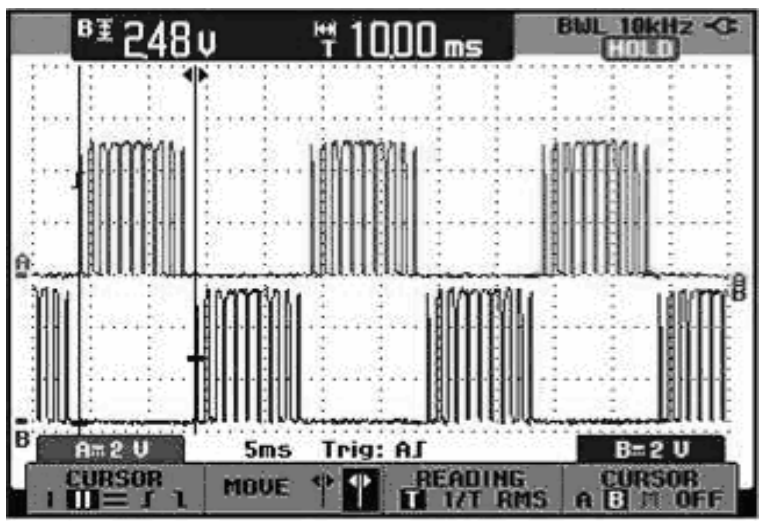

Fig. 9. FPGA pulses.

ily of programmable logic components. The architecture is composed of a matrix of CLB bordered by a ring of configurable input/output blocks. These resources communicate among themselves through a programmable interconnection network and suit the firing signal, where it is subjected to hardware-oriented constraints. The target technology uses one of the Xilinx series of FPGA. The circuit is designed using VHDL in a Xilinx integrated service environment. The module is programmed with the help of a SRAM-FPGA-based Xilinx family Spartan-3 XC3S400-4pq208, to function as a fuzzy controller. The pulses for the

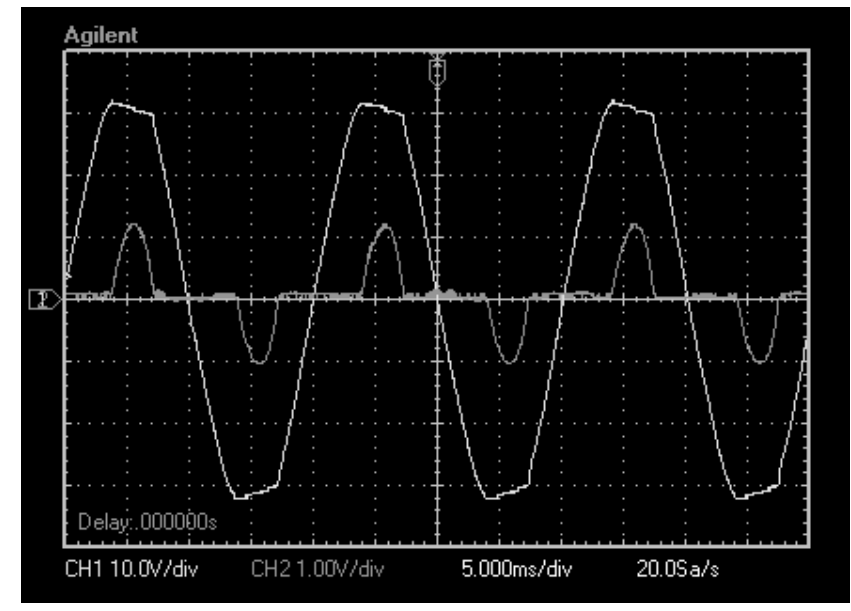

Fig. 10. Output voltage and current waveform.

Table 2. Comparison of simulation and hardware results

\begin{tabular}{|c|c|c|c|c|c|}
\hline \multirow{2}{*}{$\begin{array}{c}\text { Output } \\
\text { voltage in } \\
\text { volts }\end{array}$} & \multirow{2}{*}{$\begin{array}{c}\text { Load } \\
\text { current in } \\
\text { amps }\end{array}$} & \multicolumn{2}{|c|}{ THD in $\%$} & \multicolumn{2}{|c|}{ Input Power Factor } \\
\hline & & Simulation & Hardware & Simulation & Hardware \\
\hline 220 & 16.8 & 2.436 & 3.0 & 0.9930 & 0.99 \\
\hline 220 & 12.4 & 3.073 & 3.5 & 0.9912 & 0.98 \\
\hline 220 & 10.0 & 3.518 & 4.0 & 0.9813 & 0.98 \\
\hline 220 & 8.2 & 4.188 & 5.0 & 0.9656 & 0.95 \\
\hline 220 & 6.3 & 4.874 & 5.5 & 0.9270 & 0.93 \\
\hline 220 & 4.5 & 5.235 & 6.0 & 0.8836 & 0.90 \\
\hline
\end{tabular}

power switches are generated using the reference extracted through the FLC and the derived carrier wave. The pulses obtained from the FPGA are displayed in Fig. 9.

\section{Results and Interpretation}

The steady-state output voltage and load current waveforms captured through a digital storage oscilloscope using an attenuator probe in the ratio of 1:10 and a current transformer, respectively, corresponding to a load power of 4 $\mathrm{KW}$, are displayed in Fig. 10. The entries in Table 2 include the output voltage, load current, \%THD, and IPF over a wide range of load variations. The THD values are directly measured through a $3 \mathrm{GHz}$ spectrum analyzer (GSP830) of GWINSTEK make. The IPF values are digitally calculated through the FPGA processor. The experimental results serve to validate the proposed approach through a close comparison of the simulated and hardware results.

\section{Conclusion}

Switching pulses based on a PPWM strategy for the power switches in an ac-ac converter have been generated using an FPGA processor. The effective implementation of the designed control algorithm has been found to signifi- 
cantly enhance the power quality and regulate the output voltage of the PWM converter. The results obtained substantiate the suitability of the proposed scheme for use in critical applications such as ASDs, induction furnaces, and others, and will go a long way in extending the scope of the use of such converters.

\section{Acknowledgements}

The authors thank the authorities of Annamalai University for providing the necessary facilities to accomplish this piece of work.

\section{References}

[1] G. N. Revankar, et.al., "Symmetrical pulse width modulated ac chopper", IEEE Trans. Ind. Electron. Contr. Instrum., Vol. 24, No. 1, 1977.

[2] K. A. Krishnamurthy, et.al, "Ac power control of an RL load", IEEE Trans. Ind. Electron. Contr. Instrum., Vol. 28, No. 4, 1981.

[3] Gyu-Ha Choe, et.al., "A new pulse width modulated method for ac chopper", IEEE Power Electronics Specialists Conf. Rec., 1987.

[4] K. E. Addoweesh and A.L. Mohamadein, "Microprocessor Based Harmonic Elimination in Chopper Type AC Voltage Regulators", IEEE Trans. Power Elec., Vol. 5, No. 2, pp. 191-200, April 1990.

[5] P. N. Enjeti, P.D. Ziogas and J.F. Lindsay, "Programmed PWM technique to Eliminate Harmonics: A Critical Evaluation", IEEE Trans. Ind. Appl., Vol. 26, No. 2, pp. 302-316, March/April 1990.

[6] Lin, B.R, Hung, T.L, Huang, C.H, "Single-phase AC/AC converter with capacitor-clamped scheme', IEE Proceedings on Electric Power Applications, Vol. 150, Issue 4, 8, Page(s): 464-470, July 2003

[7] Higuchi Tsuyoshi, Yamada Kenji, Ishibashi Toshiyuki, Yamamoto Eiji, Hara Hidenori, Kume Tsuneo, Swamy. M.M, “An Environmentally Harmonious AC-AC Converter that provides Sinusoidal Waveforms", IEE Papers of Technical Meeting on Semiconductor Power Converter, Japan, Vol. SPC-04; No. 149-155; pp. 13-18, 2004.

[8] Rahmani L., Krim F., Khanniche M. S., Bouafia A., "Control for PWM ac chopper feeding nonlinear loads", International Journal of Electronics, Vol. 91, No. 3, pp. 149-163, 2004.

[9] Kawai Makoto, Ueda Akiteru, Torii Akihiro, Doki Kae, "Control Characteristic of Buck-boost AC Chopper", IEE Papers of Technical Meeting on Semiconductor Power Converter, Japan, Vol. SPC-04, No. 74-92, pp. 93-98, 2004.
[10] Tanimatsu Hiroaki, Hiraki Eiji, Tanaka Toshihiko, Nakaoka Mutsuo, Yasui Kenji, Hirota Izuo, Iwai Toshiaki, Omori Hideki, "One Stage High Frequency AC-AC Converter for Induction Heating with Power Factor Correction Function", IEE Papers of Technical Meeting on Semiconductor Power Converter, Japan Vol. SPC-06; No. 36-42.44-47; pp. 47-52, 2006.

[11] Rusalin Lucian R. Pă un, "AC-AC Converters for UPS",

[12] Fang Lin Luo; Hong Ye, "DC-Modulated Power Factor Correction on AC/AC Luo-Converter", 9th International Conference on Control, Automation, Robotics and Vision, Volume, Issue , 5-8 Page(s):1-6, Dec. 2006.

[13] Kirubakaran.D, Rama Reddy.S., "Closed Loop Controlled AC-AC Converter for Induction Heating”, Journal of Industrial Technology, Vol. 25, No. 2, June 2009.

[14] Garg.V, Singh.B and Bhuvaneswari.G., "24-pulse acdc converter for harmonic mitigation", IET Power Electronics, Vol. 2, Issue 4, pp. 364-374, July 2009.

[15] Maswood A.I. and Firmansyah. E, "Current injection in a controlled rectifier under unbalanced supply and variable line and load inductances", IET Power Electronics, Vol. 2, Issue 4, pp. 387-397, July 2009.

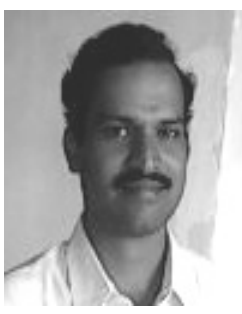

N. Radhakrishnan obtained his Bachelor's degree in Electrical and Electronics Engineering from the University of Madras in 1996 and his Master's degree in Power Systems Engineering from Annamalai University in 2005. He has nine years of teaching experience. He is currently working as Assistant Professor in the Department of Electrical Engineering at Annamalai University. $\mathrm{He}$ is on his way to obtaining his doctoral degree in Power Quality. His areas of interest include power electronics, solid-state drives, intelligent control techniques, and HVDC transmission. He published three papers in various international journals.

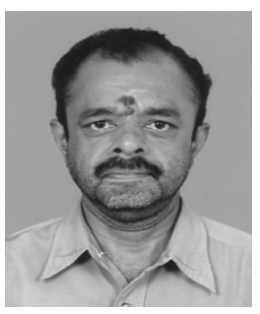

M. Ramaswamy is currently working as Professor of Electrical Engineering. He completed his B.E. Electrical and Electronics Engineering at Alagappa Chettiar College of Engineering and Technology, Karaikudi, Tamil Nadu, India, in 1985; completed his M.E. in Power Systems at Annamalai University, Tamil Nadu, India, in 1990; and completed his Ph.D. degree in Electrical Engineering at Annamalai University in 2007. He has published 13 papers in various international journals. 